\title{
African studies computer resources
}

\author{
By Patricia S. Kuntz
}

\section{Internet and beyond: African linkages}

$\mathbf{T}$ he "information highway" is very busy among Africanists around the world. Scholars based in Cameroon, Egypt, Ethiopia, Ghana, Kenya, Mali, Senegal, South Africa, Tunisia, Zambia, and Zimbabwe with colleagues in the Americas, Europe, and Asia have coordinated conferences, written research papers, and shared ideas on technology using one or more of the four computer network services.

This essay focuses on African studies computer resources available in the U.S. with linkages to Africa. Four fundamental computer systems exist: Internet/Bitnet, Fidonet, UseNet, and BBS (dial-up bulletin board services). An updated list of these network services is available from Arthur McGee. ${ }^{1}$ For a complete list of files, contact: Internet:<amcgee (-) netcom.com> <amcgee@eis.calstate.edu>BDPA BAC: [1-707552-3314] to [Arthur McGee]; Data Bits Online: [1-213-295-6094] to [Arthur McGee]; Compuserve: [72377,1351]; Voice: [1-310-320BYTE]

AFRIMAIL.MSG = Internet/Bitnet Mailing Lists AFRISITE.MSG $=$ Online Information Sites AFRINEWS.MSG $=$ UseNet Newsgroups BLACKBBS.MSG $=$ BBS List

To demonstrate the wide variety of network services available to Africanists, only a few examples will be mentioned in each category. Nevertheless, the field of information technol ogy via computers is exploding even in African countries with limited resources and conflicting political and social policies.

\section{Internet/Bitnet}

The most common network systems throughout the world are Internet and Bitnet. Internet is growing in popularity with the various compatible networks such as NetNorth (Canada), Janet (United Kingdom), and EARN (Europe). Nearly all U.S. universities and most colleges purchase a connection to the Internet. This employment benefit enables faculty, staff, and students access to File Transfer Protocol (FTP), Telnet, and UseNet. In contrast, Bitnet's main feature is the automatic conversation lists called "Listserv." One should not confuse the new software "Listserver" which is comparable for the Internet.

\section{Electronic Mail}

Both Internet/Bitnet networks provide electronic mail (e-mail) for sending public and private messages. Messages from one network system are tracked through gateways to other systems. Consequently, readers having only an Internet or Bitnet address can still send and receive messages to the other network. In fact, gateways also facilitate the use of Fidonet and UUCP technology.

For example, e-mail contacts to Africanists and inquiries concerning African studies can be made through the following organizations:

- African Studies Association (ASA): $<$ africa@emoryu1.cc.emory.edu>. One of the oldest area studies associations of academics with over 3,000 members.

- American Association for the Advancement of Science/African Academy of Science (AAAS): <afraaas@gwuvm.gwu.edu>. A joint U.S. and African association for the promotion of scientific research and technology. 
- Association of African Studies Programs (AASP): $\langle\mathrm{NA}\rangle$. An association of colleges and universities which offer a collection of courses concerning African content. This organization sponsors the summer language programs.

- Washington Office on Africa (WOA) $<$ woa $@$ igc.apc.org >. This office lobbies the U.S. Congress concerning issues of Africanists, Africans, and African-related issues.

As a result of the National Defense Education Act (1958), the U.S. Department of Education funds the following universities to teach courses, conduct research, and disseminate information about Africa throughout their respective regions. Below is a list of the current graduate and undergraduate centers for African studies (NDEA/HEA Title VI African Studies Centers):

- Boston University: not available

- Univ. of California-Berkeley: <asc@ uclink.berkeley.edu>

- Univ. of California-Los Angeles: < ? @others. sscnet.ucla.edu>

- Comell University: not available

- Univ. of Florida: <africa@nervm.nerdc. ufledu>

- Univ. of Illinois: <dcrummey@ux1 cso.uiucedu>

- Indiana University: <winchest@indiana.edu>

- Michigan State University: <africa@ msu.edu>

- Ohio State University: <mowoe.2@ osu.edu>

- Univ. of Pennsylvania Consortium: <sbarns@mail.sas.upenn.edu>

- Stanford University: <richard.roberts@ forsythe.stanford.edu>

- Univ. of Wisconsin: <afrst@macc. wisc.edu>

- Yale University: not available

Commercial companies also provide e-mail connections, in addition to a wide variety of other services such as online news, weather reports, and so forth. The largest commercial company is CompuServe, which provides CompuServe Africa service for the growing African demand for network connections, especially from southern Africa. ${ }^{2}$ Another commercial service for African news is NewsNet. ${ }^{3}$ This company has the following products among others: AFRICA NEWS, ANGOLA PEACE MONITOR, ASP DIPLOMAT, MIDEAST MARKETS, SOUTH AFRICAN FOCUS, SOUTHSCANSOUTHERN AFRICA.

\section{Distribution lists}

Another Internet/Bitnet feature is the option of creating public or private distribution lists. These consist of frequently used addresses which form an identifiable interest group. Users are obligated to discuss issues centering on the topic of the distribution list.

One type of distribution list can be developed and maintained as an extension to a private account. In this situation the list owner manually maintains the board and answers technical questions concerning list policy, topics, and software. Generally, subscribers have access to these lists free of cost. Unlike other services, these private distribution lists do not archive messages or update subscribers. An example of this feature is Michigan State University's African Studies Center biweekly newsletter. Africanists can contact the list owner, Yacob Fisseha, at his personal address: $<21248$ yf@msu.edu $>$ for inclusion on the mailing list.

The following list of lists is a sample of several African-related public distribution newsgroups. Some of the groups are open to the public while others are designed for Africans of a particular nationality or persuasion. If not specifically indicated, assume that they offer public access. Since not all list owners follow a specific subscription convention, one may need to write the board directly to obtain directions for subscription procedures.

- AAJN@catcc.bitnet. Discussion concerning Burkina Faso or those who worked in there.

- AFRIQNEWS@athena.mit.edu. African news service from various wire services and information concerning the Boston-area Africanists

- ALGERIA-NET @monte.svec.uh.edu Subscribe: <algeria-net-request@monte. svec.uh.edu>.

- AMAZIGHT-NET@engcd.bu.edu. Persons interested in Berbers and North Africa with messages accepted in English, French, and Tamazight. Subscribe: <amazight-net-request@ engcd.bu.edu>

- ARABIC-L@byu.edu. A monitored service for members and friends of the American Association of Teachers of Arabic (AATA). Discussion focuses on linguistic and pedagogical issues of Arabic.

- ASA-NET@sfu.ca. A Canadian service for African students EGYPT-NET@das.harvard.edu. Egyptian students and friends. Subscribe. <egypt-net-request@das.harvard.edu>. 


\section{A BetTer WAY To SEARCH DATABASES}

$\mathrm{WJ}_{\text {committed to better search software }}^{\text {e started }}$ design. We became the premier vendor of Medline, then expanded our catalog to other databases. Last year we won Information World Review's PRODUCT OF THE YEAR for faster, easier search software. But a better way means meeting the evolving needs - individual and campus wide - of today's library users.

A nnouncing OVID: a database interface $A_{\text {so flexible it molds itself to your search }}$ environment.

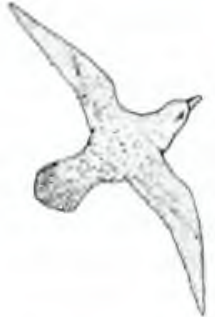

With OVID you' re free to move from one operating system to anotber without retraining. OVID's Common User Interface assures identical functionality in DOS, Windows and UNIX.

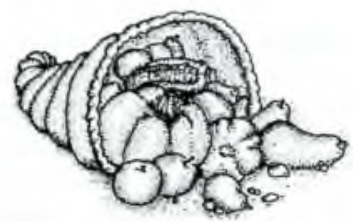

'There's an unprecedented array of search tools - indexes, thesauri, limits and fields - many never before available in an interface. They're all standard OVID features.

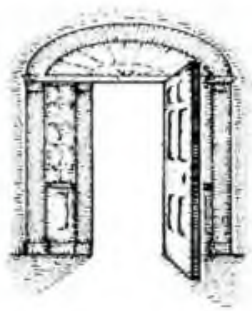

$A$ baven for beginners, OVID's

Easy Mode bas on screen prompts. The more experienced can pull-down menus showing an array of search options. Experts will feel at bome using online syntax.

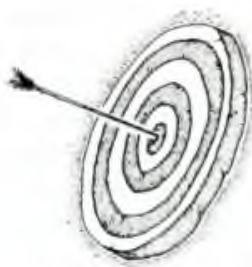

Search with natural language if you like. OVID mapping cuts through the mystery of controlled vocabularies, boming in on precisely matching subject beadings.

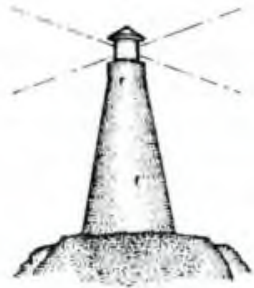

HELP for every search function is context-sensitive and on screen, never more than a key. stroke or mouse click away.

\section{OVID. A better way to search ERIC, Current Contents", PsycINFO Medline, Readers' Guide Abstracts, EMBASE and more.


service (WAIS). In addition to providing e-mail addresses, course lists, weekly announcements, and faculty addresses, this connection accesses computerized library catalog systems around the world.

The University of Pennsylvania, African Studies Consortium, has created an African studies gopher board. Readers can obtain connection through various gateways: Gopher client <gopher.upenn.edu> or FTP site $<$ FTP.upenn.edu> or Telnet - <open penninfo.upenn.edu>." To access the African Studies database follow these directions: "PennInfo," "Interdisciplinary Studies," "African Studies."

\section{Fidonet}

Fidonet is an international, decentralized, cooperative, voluntary system in which participants serve one another by relaying messages through a routing system. A list of all Fidonet nodes is updated weekly from a central point (node $1: 1 / 0$ ) and is distributed throughout the network. Since this network has no central computers, Fidonet is organized in a branching system with six geographically designated zones:

$$
\begin{aligned}
& 1=\text { USA } / \text { Canada/Mexico }- \text { North America } \\
& 2=\text { Europe } \\
& 3=\text { Australia, New Zealand (Oceana) } \\
& 4=\text { Latin America } \\
& 5=\text { Africa } \\
& 6=\text { Asia }
\end{aligned}
$$

Individuals establish Fidonet nodes using only personal computers, international speedmodems, and free software. Consequently, this process permits access to rural areas. Gateways or links have reduced the cost of transmission.

\section{Echomail}

Echomail is a specific public forum, conference group, or newsgroup. It is one of the options (having various labels) at the top menu which allows subscribers to select groups. Currently, there are four Echomail conferences of interest to Africanists:

- Africa Link-Bob Barad (Baobab BBS) links all African-related BBS which have Fidonet connectivity and choose to collaborate.

- Peace Corps-Returning Peace Corps volunteers who wish to maintain contact with volunteers in their cohort group, service area, or country assignment.
- South Africa-Discussion of the political, economic, social situation in South Africa including the Apartheid philosophy, the "transitional government," and constitutional revisions.

- Southern Africa Drought--The agricultural and environmental situation in eight southern African countries.

\section{UseNer}

UseNet is a third worldwide network that provides one main service-news. UseNet newsgroups are largely unavailable to Bitnet sites. While many of Usenet's sites are commercial, advertising is strictly forbidden on the network. Although some 3,000 newsgroups are available, not all sites carry all newsgroups. Since no files are associated with this service and messages are automatically deleted on a regular basis, UseNet provides no archiving feature characteristic of the Bitnet listserv. To create a newsgroup on UseNet, any user must secure a minimum of 100 yes votes for the news group topic. Once a news group is approved, it is difficult to remove it from the network. African-related UseNet news groups are:

rec.music.afro-latin

rec.travel

soc.culture.egyptian (proposed)

soc.culture.southafrica (proposed)

soc.culture.arabic

soc.culture.african

soc.culture.maghreb

soc.religion.islam

talk.politics.mideast

\section{Bulletin board system}

The bulletin board system (BBS) connects personal computers directly through a telephone connection. Since these boards cost the user a telephone call, unlike the academic networks (Internet/Bitnet), a long distance log-in can be expensive.

Presently, few BBSs exist for strictly African-related content. Two members of the African Studies Association have promoted the use of electronic communications in Africa and the Americas.

African Studies (1989) Patricia Kuntz (608) 262-9689, 8N1 1200-14,400 modem; Fidonet connections: $1: 121 / 25.3$ and $1: 109 / 151.42 ;$ Internet connections:@p3.f25 n121.z1.fidonet.org

Baobab (1989) Bob Barad (202) 296-9790 8N1 1200-14,400 modem; Fidonet connections: 1:109/151; Internet connections:@f151.n109. z1.fidonet.org 


\section{African linkages}

For readers seeking contacts in Africa, over 30 African countries have various network connections. These connections include Bitnet, Internet, Fidonet, OSI, UUCP. Larry Landweber (University of Wisconsin), co-founder of the Internet Society, provides a bi-annual update of the five network options for each African country among others. This information is available through the Internet Society:

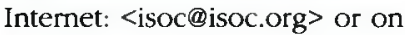

"gopher" - (Washington, DC) Internet Society

FTP <FTP.cs.wisc.edu/connectivity_table/ version_9.text>.

In addition to Landweber's list, Karanja Gakio <gakio@ftp.com> and Randy Bush < randy@ psg.com $>$ have assembled directories of specific addresses and specialized networks in Africa.'

Below is a list of the current connected African countries with Internet code and connectivity:
Algeria (DZ - UUCP)
Angola (AO - Fidonet)
Botswana (BW - Fidonet)
Burkina Faso (BF - UUCP)
Cameroon (CM - UUCP)
Congo (CG - UUCP)
Cote d'Ivoire (CI - UUCP)

Egypt (EG - Bitnet, Internet, UUCP)

Ethiopia (ET - Fidonet)

Gambia (GM - Fidonet)

Ghana (GH - Fidonet)

Kenya (KE - Fidonet)

Lesotho (LS - UUCP)

Madagascar (MG - Fidonet)

Malawi (MW - Fidonet)

Mali (ML - UUCP)

Mauritius (MU - Fidonet)

Mozambique (MZ- Fidonet, UUCP)

Namibia (NA - UUCP)

Niger (NE - UUCP)

Nigeria (NG - Fidonet, UUCP)

Reunion (RE - UUCP)

Senegal (SN - Fidonet, UUCP)

Seychelles (SC - UUCP)

South Africa (ZA - Fidonet, Internet, OSI, UUCP)

Swaziland (SZ - UUCP)

Tanzania (TZ - Fidonet)

Togo (TG - UUCP)

Tunisia (TN - Bitnet, Fidonet, Internet, OSI, UUCP)

Uganda (UG - Fidonet)

Zambia (ZM - Fidonet, UUCP)

Zimbabwe (ZW - Fidonet, UUCP)
Depending upon the official language of the country, the network service is generally associated with the colonial legacy. For instance, English-speaking countries use Bitnet, Internet, and Fidonet as popularized by the United States, Canada, and United Kingdom. For those francophone countries having UUCP service, the director of ORSTOM, Paul Renaud $<$ renaud@ostom. $\mathrm{fr}>$ can assist with connections.

\section{Conclusion}

The four computer networks described above along with the African connectivity information are fundamental tools for administrators, faculty, students, librarians, and outreach personnel interested in Africa. Proficiency in computer technology and networks is essential for readers involved in research, teaching, administration, and extension.

\section{Notes}

${ }^{1}$ Ken Onwere maintains the AfroNet <system@afrex.news.fidonet.org> or <postmaster@afronet.san-diego.ca.us>.

${ }^{2}$ News release dated September 3, 1992. In the United States contact Compuserve directly. In South Africa call (012) 841-2530 or southern Africa at (+27) (12) 841-2530.

${ }^{3}$ NewsNet: For the Business Information Edge contact: Kelly Bahel, NewsNet, Account Rep., 945 Haverford Road, Bryn Mawr, PA 19010; (215) 527-8030 or (800) 952-0122.

${ }^{4}$ Sysop is Julie Sisskind \% Sandra Barnes, Anthropology: sisskind@mail.sas.upenn.edu.

${ }^{5}$ Connectivity with Africa: URL:gopher:// gopher.psg.com:70/0/0/networks/connect/ africa.txt; <server@gopher.psg.com> subject: pub. gopher-data/networks/connect/africa.txt

\section{Compile a subject list of Internet resources}

CERL News would like to print brief subject lists of Internet resources such as the one prepared by Jeffrey A. Coon on religious studies that appeared on page 635 of the December 1993 issue. If you are interested in preparing a brief list in your area of expertise contact: Mary Ellen Davis, Editor \& Publisher, CERL News, 50 E. Huron St., Chicago, IL 60611 or e-mail: U38398@uicvm.uic.edu. 


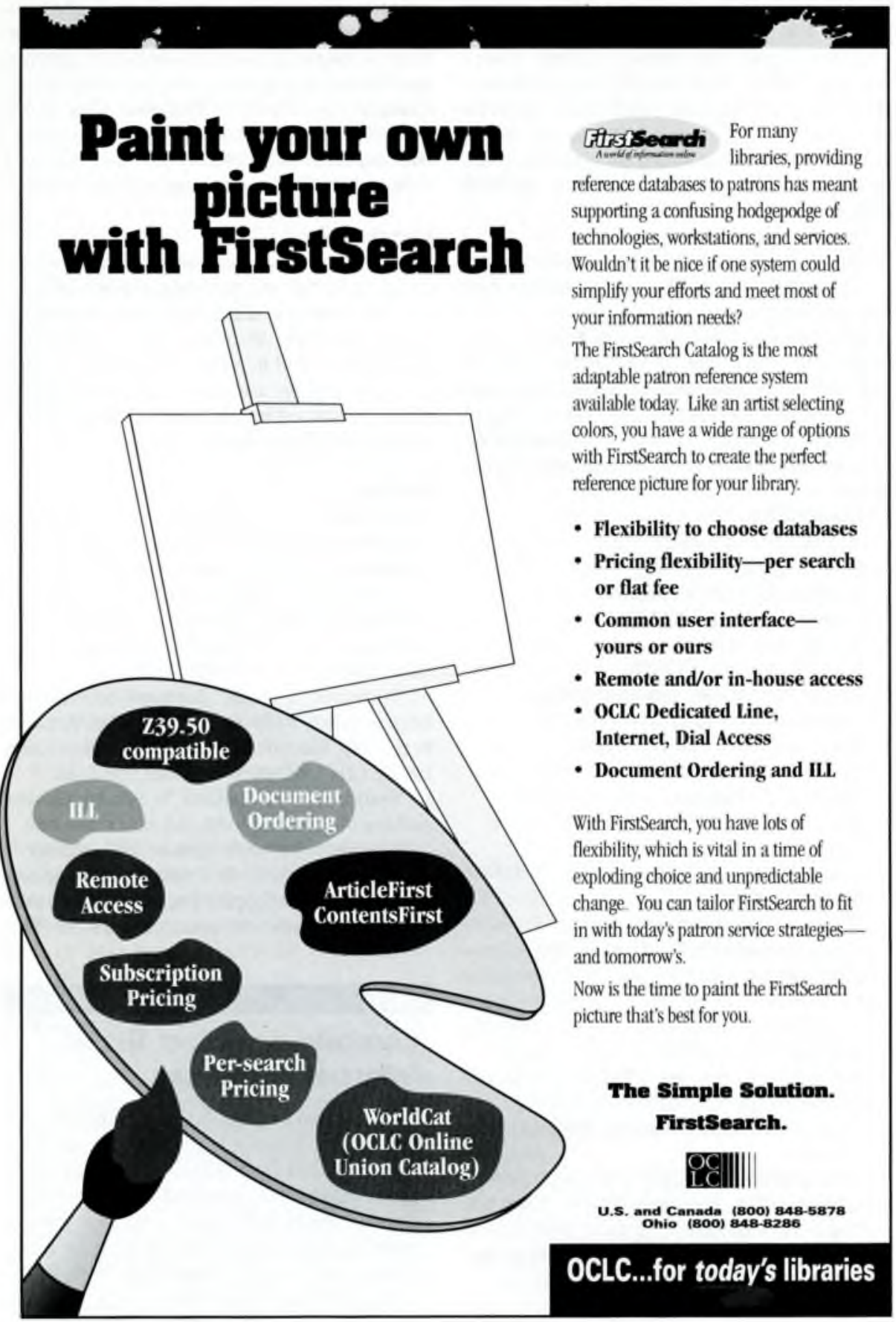

